MATHEMATICAL ASSOCIATION

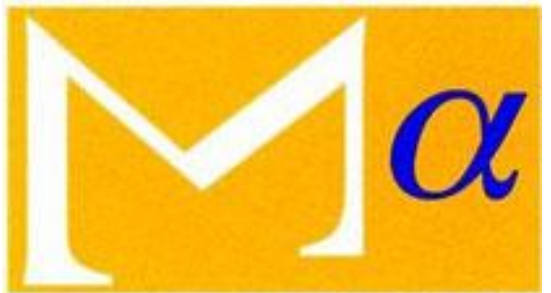

supporting mathematics in education

The Nature of Elementary Mathematics from the Modern Standpoint

Author(s): C. Elliott

Source: The Mathematical Gazette, Vol. 6, No. 96 (Jan., 1912), pp. 219-220

Published by: The Mathematical Association

Stable URL: http://www.jstor.org/stable/3604308

Accessed: 13-03-2016 03:56 UTC

Your use of the JSTOR archive indicates your acceptance of the Terms \& Conditions of Use, available at http://www.jstor.org/page/ info/about/policies/terms.jsp

JSTOR is a not-for-profit service that helps scholars, researchers, and students discover, use, and build upon a wide range of content in a trusted digital archive. We use information technology and tools to increase productivity and facilitate new forms of scholarship. For more information about JSTOR, please contact support@jstor.org. 
type have their place in mathematics, and that the development from the lower to the higher should be a transition naturally made by a mind seeking greater efficiency and economy in its thinking. ${ }^{1}$

T. P. Nuns.

\section{THE NATURE OF ELEMENTARY MATHEMATICS FROM THE MODERN STANDPOINT.}

THE character of the modern treatment of elementary mathematics is such that mathematics might reasonably be described as the Science of Classification. The mathematician may be supposed to begin as a collector, whether of butterflies, minerals, or even of cigarette cards, does not matter. Let us consider that he has collected so many different kinds of things as to become virtually a collector of collections, each collection having its own classification, and that his next step is to compare these classifications with each other, that is, to become a classifier of classifications. The mere comparison of classes requires the idea of cardinal number, since the only thing which can be said about two classes, irrespective of the nature of their individual nembers, is the number of individuals in each class. But the comparison of classifications which do not consist merely of single classes introduces ideas which are essential to the further development of the idea of number, and to the development of Geometry, and which should therefore precede that development. It is in this super-classification or comparative study of classifications that the foundations of mathematics are to be sought, and the question therefore arises, whether the presentation of the rudiments of mathematics should not be modified so as to recognize this fact. Of the fundamental ideas of matheruatics, four especially, namely those of correspondence, order, group, and of multiple correspondence, seem to lend themselves, in their elementary treatment at any rate, to the method in which they are regarded as belonging to the Science of Classification; and will be considered in that light here, the last three being regarded as developments of the first.

Needless to say, this description of the evolution of mathematics does not agree either with the history of mathematics, as commonly given, or with the stages of mathematical instruction in schools. It must be observed, however, that the historian of mathematics is influenced by his views as to the nature of mathematics, and that the appearance of works like J. W. Young's Fundamental Concepts of Algebra and Geometry, suggests that even the traditional course may be about to undergo changes. It is true that the author of that book considers that the modern treatmeut of elementary mathematics demands too high powers of abstraction to be employable in schools in the form in which it is usually presented, namely, as a system of deductions from a comparatively small number of unproved axions or assumptions about undefined ternis. This treatment is of such a generalized character that both ordinary algebra and ordinary geometry may be among the implications of the same set of axioms, so that the two subjects may be said to have become fused into one.

Now, while admitting that it is not necessary in school work that the number of undefined terms and unproved statements should be reduced to a mininum, yet, since the ideas now accepted as being really fundamental can be understood by practical exercises in the sumie way as those which are not fundanental, there seems no reason for the almost exclusive attention paid to the latter in schools. The learner at present begius with the construction

\footnotetext{
1 See also Section VI. of the article on Wallis in the Mathematical Gazetle for February, 1911.
} 
and measurement of diagrams, with paper folding, and other practical exercises familiar to teachers. These exercises yield experimental facts, and indicate the kind of implications which it is desirable that the axioms of geometry should contain. But to learn the names and properties of the more important types of classifications presents no harder task, since it too can be accomplished with the aid of practical exercises in classification, as well as of those numerous illustrations which both school and everyday life afford, quite apart from what is commonly regarded as mathematics. Models of a duplex, triplex, and quadruplex can be made from pieces of cardboard properly coloured and shaped, and by similar models can be understood the true meaning of the all-important terms Correspondence and Order. For a correspondence, or function, or correlation, may be explained as a classification and cross-classification of the things which correspond. And again, since when like things appear on both sides of a correspondence they are in general arranged as it were in a chain, of which the correspondence supplies the links, it is also to classification and cross-classification that we turn for an explanation of the idea of order.

Among the common examples of a duplex may be mentioned the classification of nouns by declension and case, that of simple salts by metal and acid radical, that of cards in a pack by suit and value. Among the examples of functions, the correspondence of English and French words in an EnglishFrench Dictionary, of parents to children, of subject and object, of a transitive verb. These illustrations and the use of models would, if necessary, afford sufficient material by themselves for the introduction of terms like variable, direct and inverse, product, power, and others, and for the symbolic statement of a correspondence between two variables, without reference either to arithmetic or to geometry in the common sense. Indeed, it is logically necessary to consider the meaning of multiplex and of order separately before combining them to consider an ordered multiplex or "space" of which the classified things form the "points." A pupil who acquired his geometrical ideas in this order would naturally look upon geometrical instruments like set-square and metre rule, as playing a part similar to that of scissors and paint brush in constructing the model of a multiplex.

The third important idea in elementary mathematics, that of a Group, links itself to that of correspondence in the fact that a Group may be looked on as a correspondeuce not of things to other things, but of things to functions. A correspondence of things to functions need not be a Group, but every Group can be regarded as an instance of such a correspondence, and therefore as arising from a classification and cross-classification.

In the case of a Group, the variable stands for things when one side of the correspondence is in question, and for functions when the other side is in question, but in both instances, and in all the examples above, it stands for any member of a simple class. Now the peculiarity of multiple correspondence, which we take as the fourth important idea, and which is the foundation of Multiple Algebra, lies in the fact that the variable stands not for a member of a simple class, but for a member of a duplex, triplex or other multiplex. On either side of the correspondence we have not a simple class but a multiplex. The symbolic notation for a multiple correspondence must therefore depend on the one hand on that adopted for representing the position of a thing in a multiplex, and, on the other hand, on that adopted for representing correspondence. And, likewise, the extent to which the idea may be introduced into elementary work is limited by the need for a clear understanding of the meaning both of a multiplex, and of a correspondence. It remains for teachers to discover how far the use of models and of simple illustrations is adequate to furnish these ideas.

C. ElLiot"t. 